\title{
Non-Neoplastic Axillary Disorder
}

National Cancer Institute

\section{Source}

National Cancer Institute. Non-Neoplastic Axillary Disorder. NCI Thesaurus. Code C35747.

A non-neoplastic disorder that affects the structures of the axilla. Representative examples include axillary lymphadenitis and axillary abscess. 